\title{
GASTRIC FUNCTION IN CASES OF GASTRIC AND DUODENAL ULCER
}

\author{
By GARNETT CHENEY AND ARTHUR L. BLOOMFIELD
}

(From the Medical Department, Stanford University, School of Medicine, San Francisco)

(Received for publication November 14, 1927)

Although the association of high gastric acidity with certain cases of gastric and duodenal ulcer has long been recognized, the question of whether there are any findings on gastric analysis constant enough to be of real diagnostic value has never been settled. The figures in the literature cover a wide range; in most series of ulcer cases hyperacidity is said to have been present in 30 to 70 per cent of the patients, whereas the remainder showed normal or subacidity. Palmer (1) has recently reviewed the question of anacidity with gastric ulcer. Some writers would relate the tendency to hyperacidity with position of the ulcer near the pylorus or with other factors. Hurst (2) is impressed by the occurrence of duodenal ulcer only in people who already have a hyperacidity. Brown (3) has recently summarized the question as follows: "Somewhat less than 50 per cent of patients show high normal or hyperacid conditions. In rather more than $\mathbf{5 0}$ per cent of cases the figures are well within normal limits; occasionally subacidity occurs and rarely anacidity."

In regard to the volume of secretion even less definite information is available. The presence of large volumes has been assumed in certain instances of ulcer but the absence of methods for volume determinations has made any accurate comparisons with the normal impossible.

In summary, then, the general implication of the literature is to the effect that no constant or characteristic findings on gastric analysis are associated with peptic ulcer.

In a series of recent papers, Bloomfield and Keefer (4) draw attention to the inadequacy of the current methods of studying gastric function by means of the ordinary fractional test. Using a new procedure which made it possible to estimate, under uniform conditions 


\begin{tabular}{|c|c|c|c|c|c|c|c|c|c|c|}
\hline & 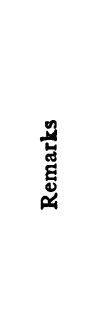 & 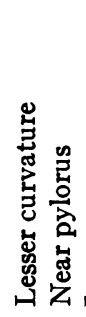 & 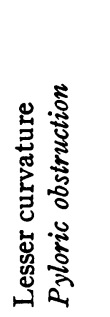 & 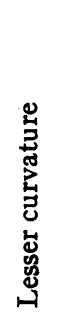 & 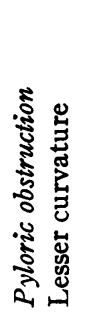 & 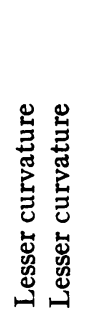 & 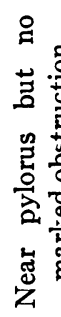 & 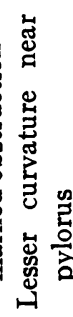 & 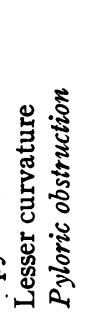 & 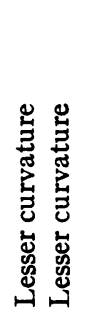 \\
\hline & 窎 & 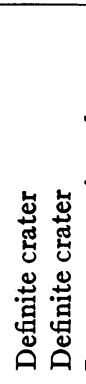 & 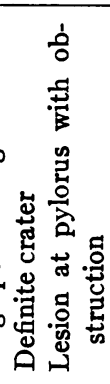 & & 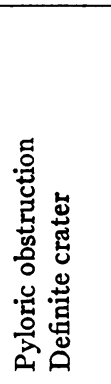 & 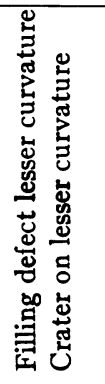 & & 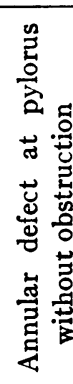 & 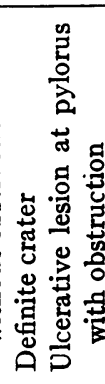 & 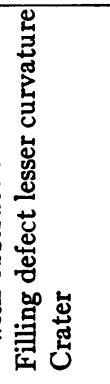 \\
\hline 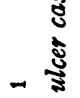 & 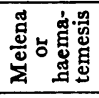 & 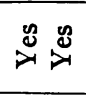 & $\stackrel{\infty}{\Delta}$ & & & $\stackrel{\infty}{\infty}$ & $\stackrel{\otimes}{\not}$ & $\stackrel{\infty}{\infty}$ & & 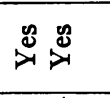 \\
\hline 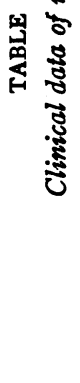 & 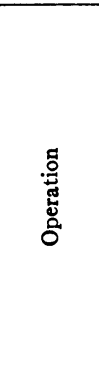 & & 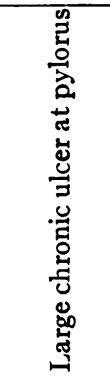 & 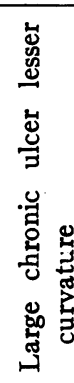 & 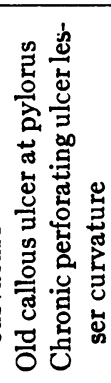 & 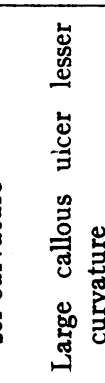 & 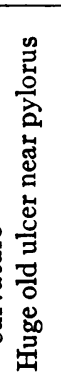 & 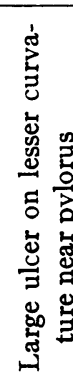 & 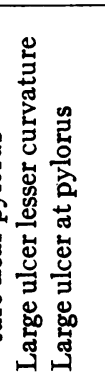 & 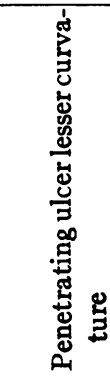 \\
\hline & 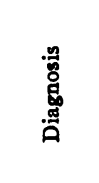 & 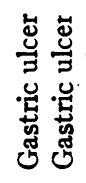 & 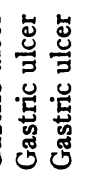 & 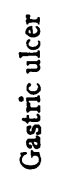 & 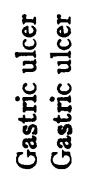 & 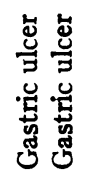 & 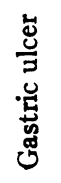 & 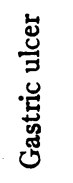 & 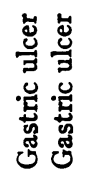 & 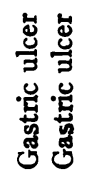 \\
\hline & : & 이 이 & ) & 9 & 象只 & 요 8 & $\overrightarrow{0}$ & กัช & 8 8 & ల్లి \\
\hline & ڤั & ¿ذا & ن̀ & $\dot{\Sigma}$ & غ் & $\dot{\Sigma} \dot{\Sigma}$ & $\dot{\Sigma}$ & $\dot{\Sigma}$ & $\dot{\Sigma} \dot{\Sigma}$ & L्य \\
\hline & ðٌ & $-\tau$ & $+n$ & 0 & $-\infty$ & ㅇㅇㅇ & $\exists$ & $\simeq$ & $\ddot{z}$ & உ2요 \\
\hline
\end{tabular}




\begin{tabular}{|c|c|c|c|c|c|c|}
\hline 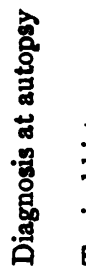 & \multicolumn{2}{|c|}{ 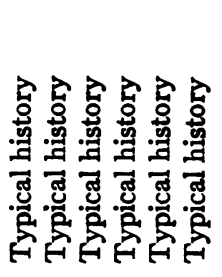 } & \multicolumn{2}{|l|}{ 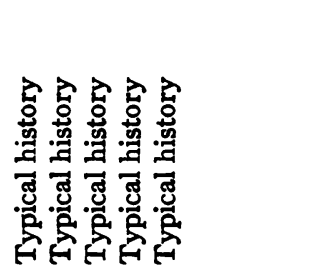 } & 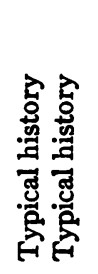 & 惫兽 \\
\hline & 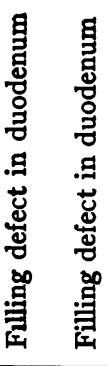 & 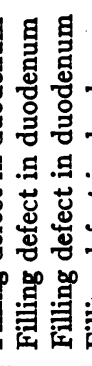 & 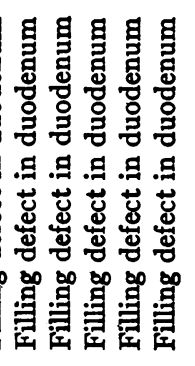 & 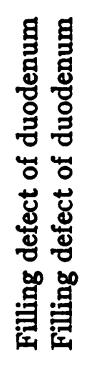 & 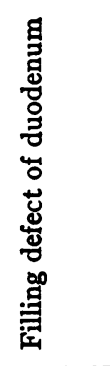 & 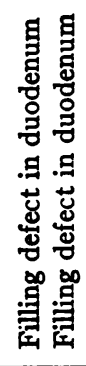 \\
\hline 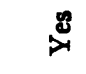 & 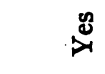 & $\sum_{i}^{\infty}$ & 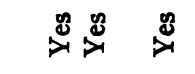 & & & $\stackrel{\infty}{>}$ \\
\hline 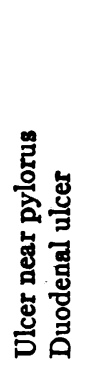 & 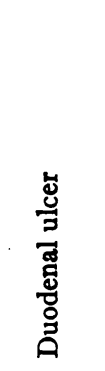 & & & 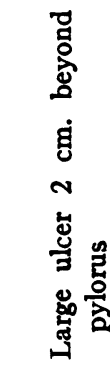 & 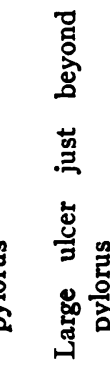 & \\
\hline \multicolumn{5}{|c|}{ 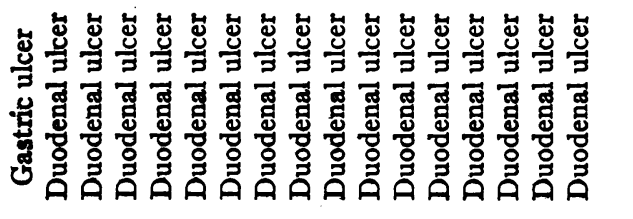 } & 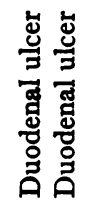 & 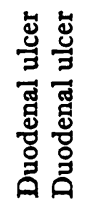 \\
\hline \multicolumn{5}{|c|}{ 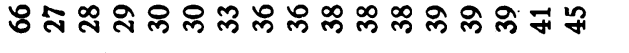 } & + 8 & 99 \\
\hline \multicolumn{5}{|c|}{ 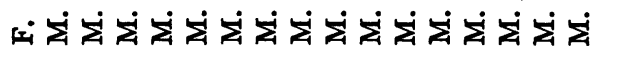 } & 㞱宅 & 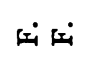 \\
\hline \multicolumn{5}{|c|}{ ニ } & Ðే ఊ్ల & \\
\hline
\end{tabular}


and with reasonable accuracy, the acidity of the undiluted gastric juice, the volume of secretion and the emptying time, after a standard stimulus (50 cc. of 7 per cent alcohol), they determined the normal variations and, in general, set standards with which the findings in instances of gastric disease might be compared. Application of these methods in a few cases of peptic ulcer (5) revealed a distinct group of findings and served as a stimulus for further observations. The present report deals with gastric functional studies in a larger series of cases of gastric and duodenal ulcer.

\section{MATERIAL}

Thirty-seven consecutive instances of peptic ulcer were studied. It seemed essential to include no questionable cases. The diagnosis was confirmed either by operation or by unequivocal $\mathrm{x}$-ray evidence together with bleeding. In every case the diagnosis was made and the patient was accepted for the series before the gastric analysis was done in order that the latter might play no part in influencing our opinion. The main facts of clinical importance are summarized in table 1.

\section{METHODS}

Studies of gastric function were carried out by the method which has been previously described in detail (6). The curve of acidity, the volume of secretion, the gastric volume curve and the emptying time were determined following the standard alcohol stimulus.

RESULTS

Acidity. The heavy line in chart 1 shows the average acidity of the gastric juice at various age periods in a control group without organic disease of the stomach. It has already been pointed out (4) that acidity on the whole diminishes with advancing years, and in considering the findings in disease this fact must be taken into account. Each dot in chart 1 indicates the highest acidity of the pure juice after the alcohol stimulus in a different case of peptic ulcer, plotted in relation to the age of the patient. That the acidity in every instance but one was above the average is strikingly shown and the line of average acidity in the ulcer cases (broken line) brings this fact out even more 
clearly. There seems to be little question but that when the acidity of the pure juice is determined, with elimination of the factors of dilution by test meal and neutralization by the buffers of saliva and test meal, high values are found to be present with great uniformity. In one case, (no. 14) there was absence of free hydrochloric acid and the

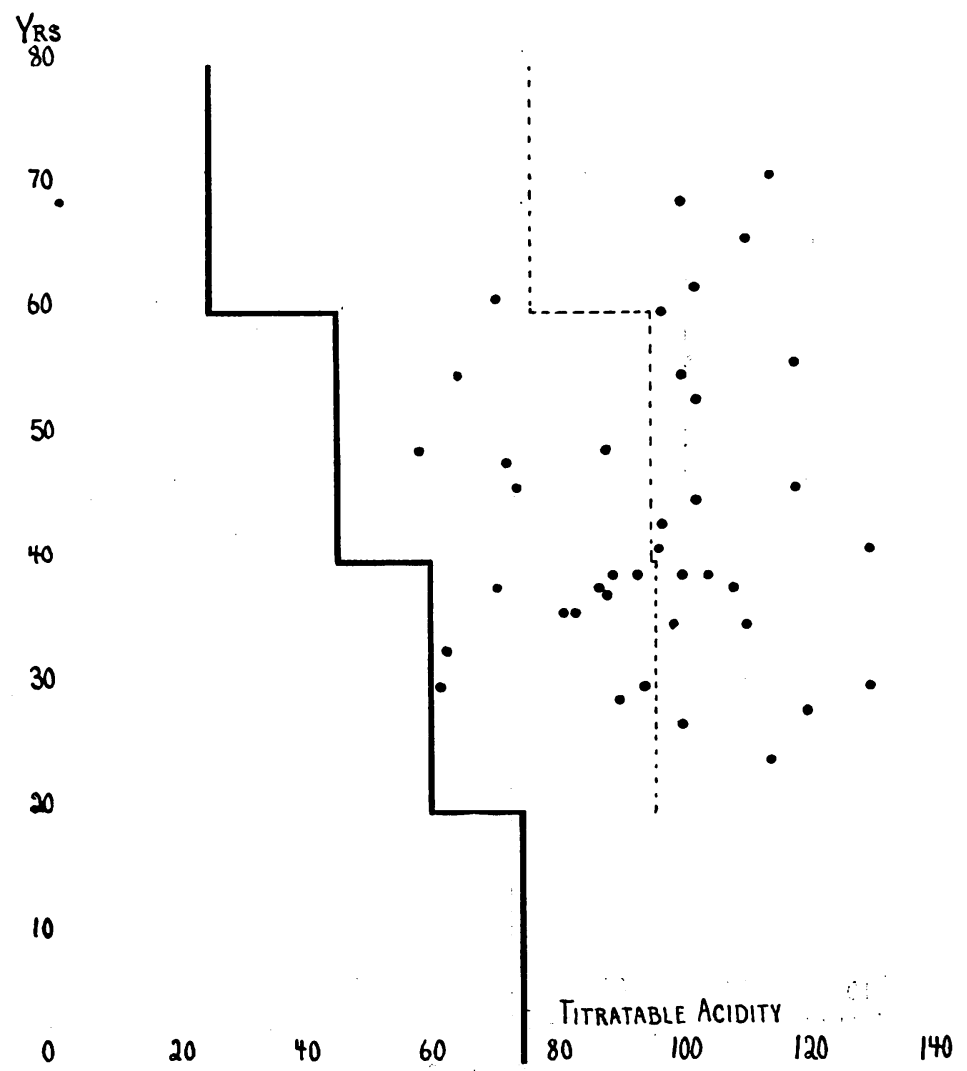

Chart 1. Relation of Acmity to Age in Ulcer Cases

$\mathrm{pH}$ of the gastric juice (colorimetric method) was found to be above 6.0. A simple gastric ulcer was found at operation, and autopsy later confirmed the diagnosis. No striking changes were discovered in the mucous membrane of the stomach. A note on this patient has been published (7). 
Volume of secretion. In chart 2 each dot represents the maximum ten-minute volume of gastric secretion following the standard alcohol stimulus, plotted in relation to the age of the patient. The heavy black line indicates the average ten-minute volume of secretion of the controls in various age periods. Here again one sees that in practically every case the volume of secretion in people with peptic ulcer is above the normal average.

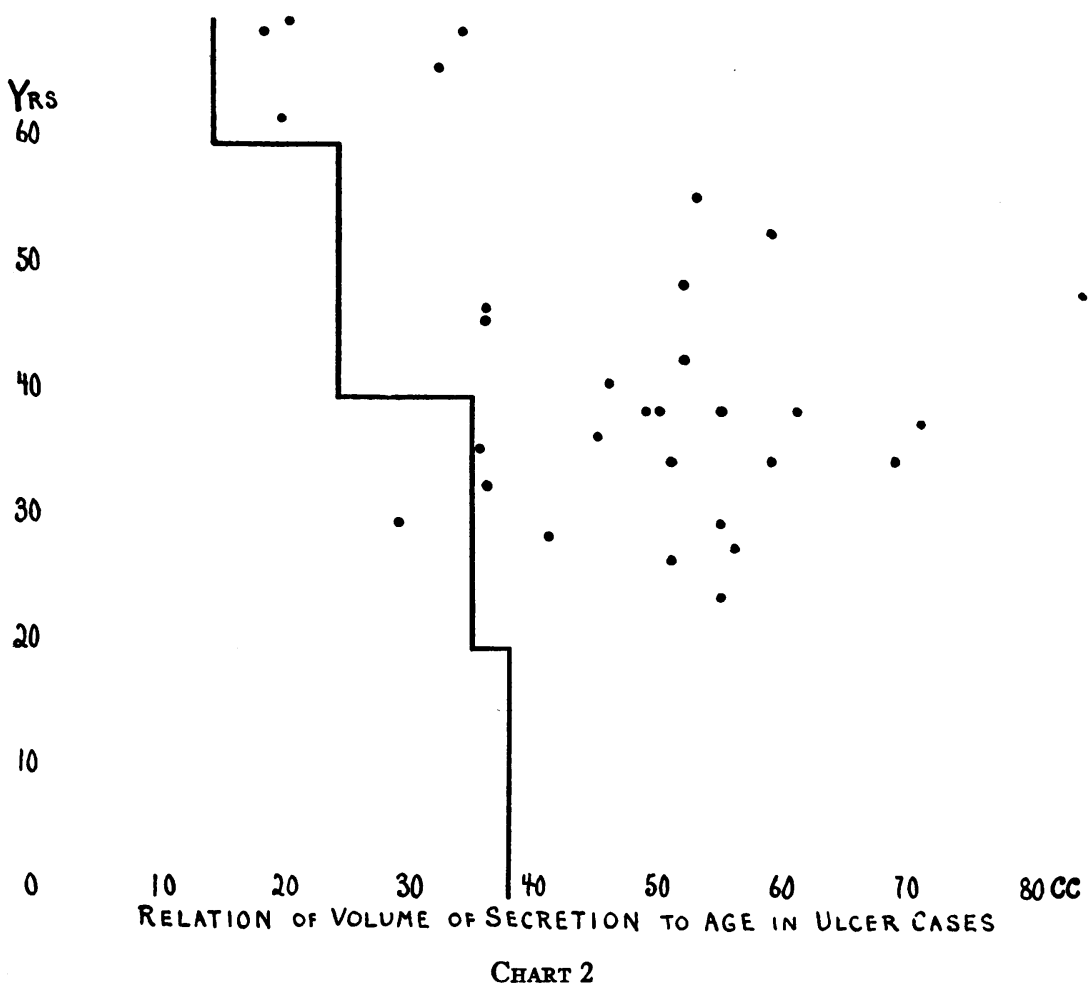

Motility. Various disorders of gastric motility have been described in connection with peptic ulcer. Actual pyloric stenosis, when marked, constitutes, of course, a definite clinical entity with distinctive features. To what extent the motility is disturbed by ulcer which has not led to pyloric occlusion is less clear. The present observations are based on complete aspirations of the entire gastric contents at ten-minute intervals after introduction of the $50 \mathrm{cc}$. alcohol meal. 
A $10 \mathrm{cc}$. sample is retained and the remainder is immediately returned to the stomach. This procedure makes possible the plotting of curves

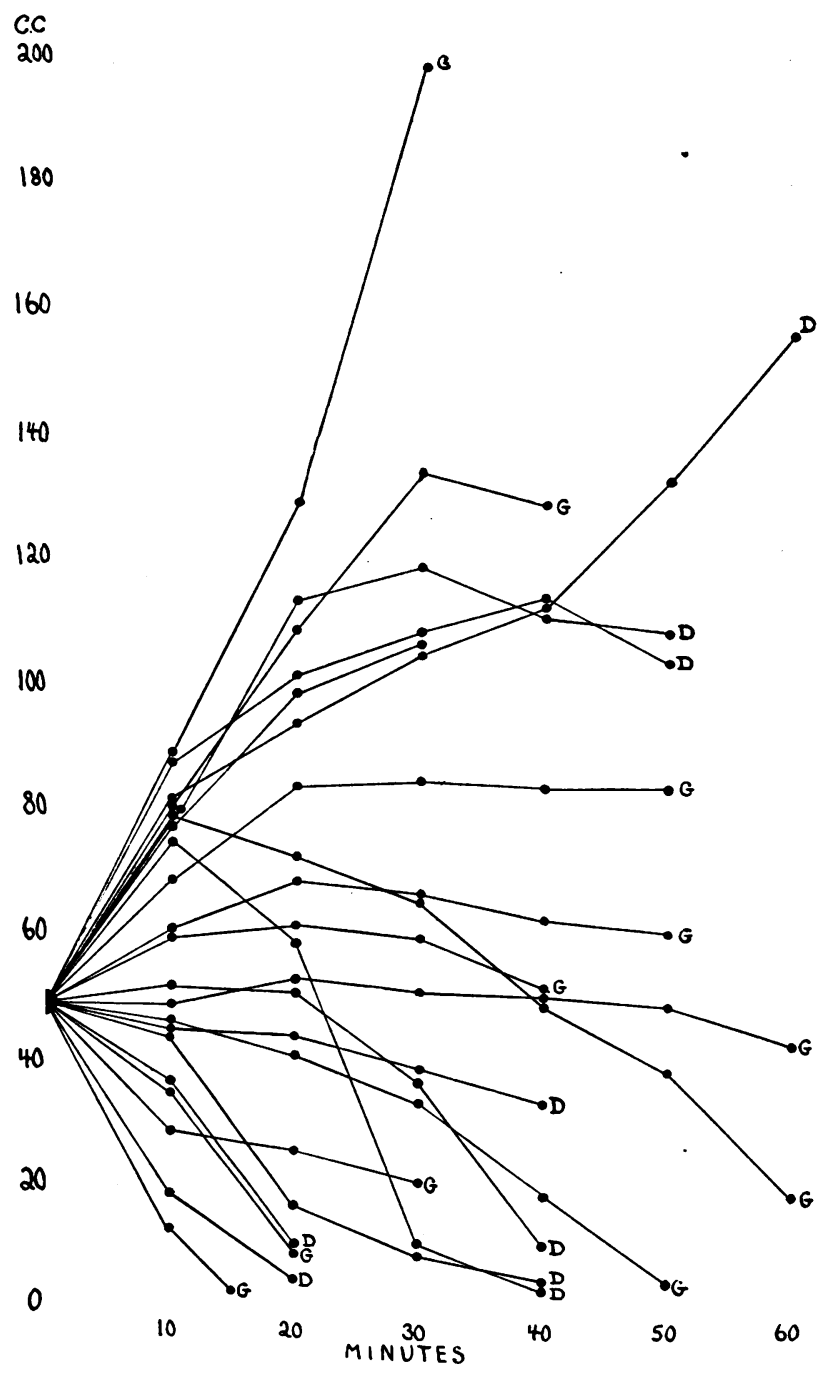

Chart 3. Volume Curves in Ulcer Cases

of gastric volume; a series from a group of control cases has already been published (4). In chart 3 are shown such curves from cases of 


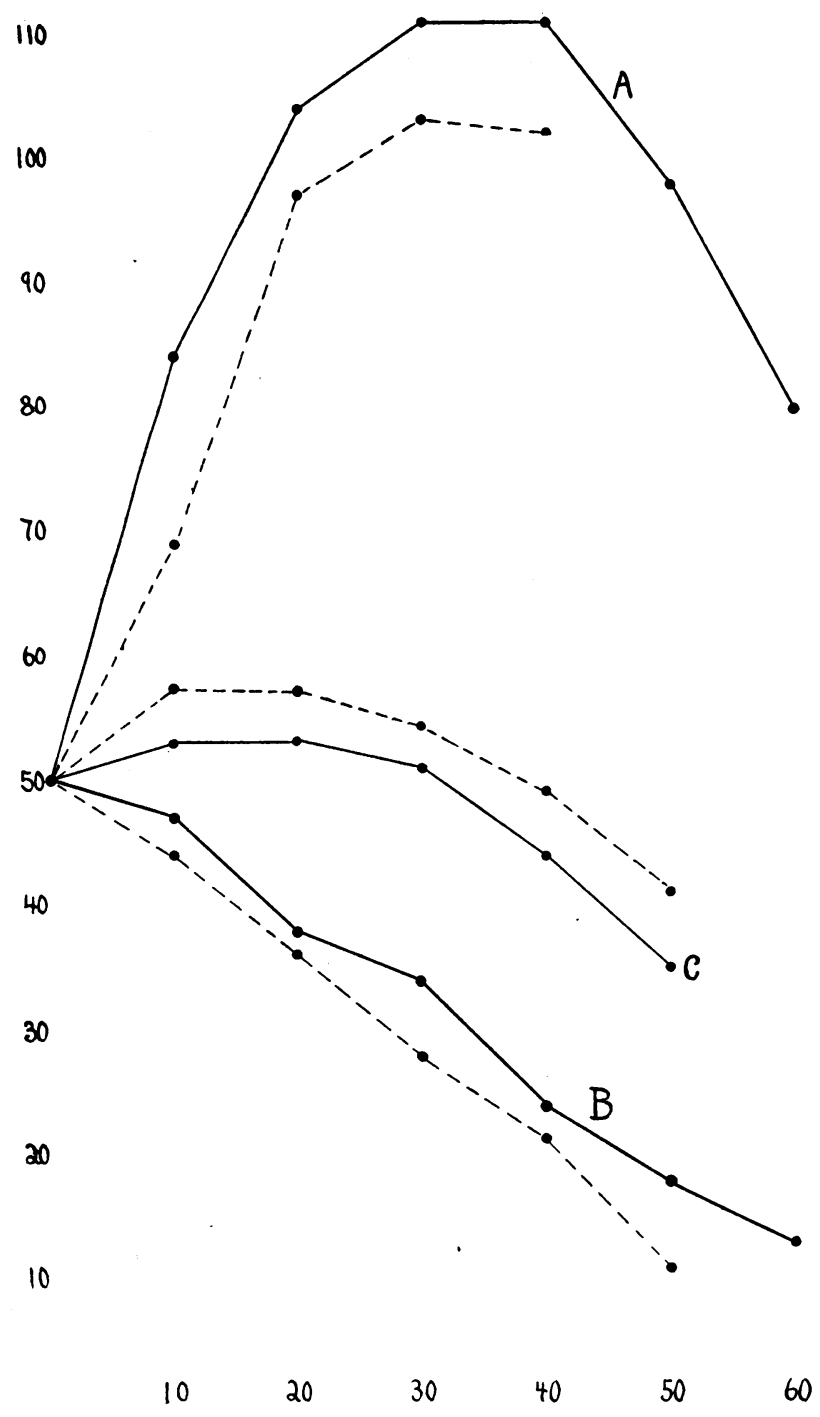

Chart 4. Composite Volume Curves

peptic ulcer. As in the control group several types are manifest: there may be an initial rise later followed by emptying, the volume may immediately decrease, or there may be an intermediate type of 
curve. In chart 4 the solid lines represent composite graphs of the volume curves in the controls without disease of the stomach: curve $\mathrm{C}$ of all the cases, curve $\mathrm{A}$ of all cases showing an initial rise and curve $B$ of all cases showing an initial fall. The dotted lines represent similar composite graphs of the curves shown in chart 3. It appears that motility in peptic ulcer cases as revealed by the present methods is practically identical with motility in the control group.

\section{COMPARISON OF FINDINGS IN GASTRIC AND DUODENAL ULCER}

On referring to table 1 one is struck by the fact that the gastric ulcer patients on the whole were older than those with duodenal ulcer. The age of the former averaged 57 years; of the latter 38 years. The same general conditions, however, as regards acidity and volume of secretion held in the two groups. The average acidity in the gastric ulcer cases was 90 ; in the duodenal ulcer cases 99 ; the average tenminute secretory volume in the former was $46.5 \mathrm{cc}$, in the latter 43.0 cc. The series is not large enough to justify conclusions as to differences of motility in the two groups. However, reference to chart 3 shows that every type of volume curve was obtained both in gastric and duodenal ulcer cases.

\section{DISCUSSION}

The purpose of the present work has been to make an objective comparison of gastric function using a standard method in a series of verified instances of gastric and duodenal ulcer and in a control group. It appears that ulcer cases with one exception showed higher acidity and larger volumes of gastric juice than the average figures for the controls in the various age periods. Motility on the whole showed no special features in the ulcer cases.

Throughout this work we have kept in mind the question of the practical diagnostic value of these findings. It has already been shown that great variations exist in the gastric findings in people without organic disease of the stomach. The mere presence of high acidity and large volume of secretion is therefore not prima facie evidence of ulcer. Whether people with this type of gastric activity are especially susceptible to ulcer as Hurst (2) suggests, will be discussed in a future communication. The absence of high acidity and 
large volume, on the other hand, we believe to be of the utmost importance in ruling out the presence of benign ulcer. In cases of indigestion, for example, with doubtful radiological signs, absence of high values for acidity and volume are very strong evidence against ulcer. The question of whether the high acidity is antecedent or consequent to the ulcer and the entire matter of the etiology of peptic ulcer are now under investigation and will be discussed in another paper.

\section{CONCLUSIONS}

1. Study of gastric function by a standard method shows that in verified cases of gastric and duodenal ulcer gastric acidity and volume of gastric secretion are greater than in people without gastric disease. These findings, with one exception, were uniform in a series of 37 cases.

2. No special characteristics of gastric motility in ulcer cases were discovered.

\section{BIBLIOGRAPHY}

1. Palmer, W. L., Arch. Int. Med., 1926, xxxviii, 603. The Mechanism of Pain in Gastric and Duodenal Ulcers.

2. Hurst, A. F., Lancet, 1922, ii, 1369 . Hypersthenic Gastric Diathesis and the Pathology, Prophylaxis and Treatment of Duodenal Ulcer.

3. Brown, T. R., Cecil, Text-Book of Medicine, 1927, p. 655.

4. Bloomfield, A. L., and Keefer, C. S., J. Clin. Investig., 1928 v, 285. Gastric Acidity: Relation to Various Factors such as Age and Physical Fitness. Also, J. Clin. Investig., 1928, v, 295. Gastric Motility and the Volume of Gastric Secretion in Man.

5. Keefer, C. S., and Bloomfield, A. L., Am. J. Med. Sc., 1927, clxxiii, 460. Observations on Gastric Function in Digestive Disorders.

6. Bloomfield, A. L., and Keefer, C. S., J. A. M. A., 1927, Laxviii, 707. Clinical Studies of Gastric Function.

7. Cheney, G., Calif. and Western Medicine, 1927, xxvii, 78. Peptic Ulcer and Achlorhydria; Case Report. 